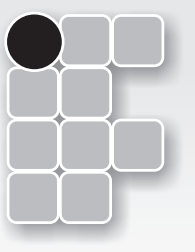

\title{
ANÁLISE SOCIOAMBIENTAL DASTRANSFORMAÇÕES DA PAISAGEM A PARTIR DA EXPLORAÇÃO DE RECURSOS MINERAIS
}

Polliana Bezerra de Oliveira ${ }^{1}$

André Carlos Silva²

Idelvone Mendes Ferreira ${ }^{3}$

\section{Resumo}

A compreensão do espaço geográfico segundo os aspectos social e natural desafia as pesquisas e, de igual modo, valoriza a Geografia na medida em que o avanço do sistema econômico capitalista traz consigo mudanças nas relações sociais, ambientais, políticas e científicas, influenciando a reorganização do espaço. Nesse sentido, o presente estudo busca estabelecer uma discussão acerca das transformações na paisagem a partir de empreendimentos mineradores e como esta exploração reflete na materialidade das questões socioambientais da contemporaneidade. Uma discussão que tem como elemento central a explotação de urânio no Município de Caetité (BA), implementada pelas Indústrias Nucleares do Brasil (INB), empresa mista, vinculada à Comissão Nacional de Energia Nuclear (CNEN) e subordinada ao Ministério da Ciência e Tecnologia, encarregada, de promover, no país, a exploração do urânio, da mineração à fabricação do combustível que gera energia elétrica nas usinas nucleares.

Palavras-chave: Aspectos socioambientais. Caetité. Mineração. Paisagem.

\section{Introdução}

As interações entre humanos e natureza proporcionam transformações no espaço, um processo carregado de intencionalidades econômicas, sociais, políticas, culturais, dentre outras. Essa relação também se configura através da cristalização das paisagens.

Segundo Santos (1997), paisagem é um conjunto heterogêneo de formas naturais e artificiais; é formada por frações de ambas, seja quanto ao tamanho, volume, cor, utilidade, ou por qualquer outro critério. Para o autor, a paisagem é sempre heterogênea.

A vida em sociedade supõe uma multiplicidade de funções e, quanto maior o número destas, maior a diversidade de formas e atores. Quanto mais complexa a vida social, tanto mais se distancia de um mundo natural e se dirige a um mundo artificial. (SANTOS, 1996, p. 65).

Até a década de 1990, nas localidades rurais do Distrito de Maniaçu, Município de Caetité (BA), predominavam as paisagens típicas das atividades agropecuárias tradicionais (pecuária e agricultura de subsistência). A paisagem era marcada exclusivamente pela vegetação natural da Caatinga imbricada nas sedes das fazendas ou nas pequenas propriedades rurais, que, por sua vez contavam com o contingente humano que nela vivia, criação dos rebanhos bovinos, e plantações de mandioca, milho, feijão e cana-de-açúcar, destinados para o sustento familiar ou a produção simples de mercadorias. A atividade agropecuária se configurava como a principal fonte econômica até então do Município de Caetité (BA).

\footnotetext{
${ }^{1}$ Mestranda do Programa de Pós-Graduação em Geografia na Universidade Federal de Goiás - Campus Catalão. E-mail: geopollyana@yahoo.com.br

${ }^{2}$ Docente do Programa de Pós-Graduação em Geografia Universidade Federal de Goiás - Campus Catalão. E-mail: andrecarlos@catalao.ufg.br

${ }^{3}$ Docente do Programa de Pós-Graduação em Geografia Universidade Federal de Goiás - Campus Catalão . E-mail: idelvoneufg@gmail.com
} 
A descoberta da reserva de urânio na Bahia ocorreu em 1976, e sua explotação ${ }^{4}$ se iniciou no ano de 2000, o que possibilitou transformações para a economia municipal, remodelando suas paisagens agrárias e urbanas. Essa atividade se instala territorialmente nas áreas próximas às comunidades ${ }^{5}$ de Juazeiro, Riacho da Vaca e Barreiro. Como o espaço é constituído pela paisagem e as relações sociais que a modelam, a atividade usou a mão de obra local, sobretudo em atividades que dependiam do trabalho braçal e conhecimento da área (mateiros).

Assim, o principal objetivo desse trabalho, que compõe a pesquisa desenvolvida no Programa de Pós-Graduação em Geografia da Universidade Federal de Goiás / regional Catalão, é propor uma discussão, acerca das transformações na paisagem a partir de empreendimentos mineradores e como esta exploração reflete na materialidade das questões socioambientais da contemporaneidade. Para o cumprimento das atividades da pesquisa, optou-se pela abordagem dialética por pretender analisar a relação sociedade/natureza pelas características das contradições do sistema econômico vigente. Essa abordagem permite entender as implicações ambientais dentro do processo em constante transformação, onde atua a ação desigual do ser humano em relação à natureza no tempo e espaço.

Destarte, o espaço das comunidades pesquisadas e consequentemente do Município de Caetité (BA), estão se modificando. A mineração de urânio condicionou transformações à Geografia desses lugares, visto que, na paisagem, as edificações da usina, as máquinas e o fluxo de caminhões e tratores que chegavam e saíam tomaram, em parte, o lugar da vegetação nativa da Caatinga, dos animais e do próprio roçado de culturas de subsistência.

Nesse sentido, esse estudo busca analisar paisagens humanizadas tradicionais, típicas das ações voltadas para a reprodução da agropecuária, e suas transformações, sobretudo para as comunidades próximas ao empreendimento minerador: Juazeiro, Barreiro e Riacho da Vaca.

\section{Mineração e as transformações socioespaciais}

As mineradoras influenciam a transformação da paisagem, pois são grandes consumidoras, interferem no processo produtivo e estabelecem ligações com outras empresas, criando e recriando ações, integrações e efeitos ambientais, tanto no que se refere à dimensão econômica e social, quanto à dimensão política e cultural.

No contexto da mineração, o Brasil vem se destacando como o segundo maior exportador mundial, em 2012 foram US $\$ 57$ bilhões de dólares, o que gerou um superávit de US $\$ 29,550$ bilhões de dólares. Um crescimento que alcança a marca de $550 \%$ e que traz a perspectiva de crescimento em média três a quatro vezes até 2030, segundo o Plano Nacional de Mineração - PNM 2030.

O estado da Bahia lidera a classificação entre os estados brasileiros com atividade mineral, segundo o Departamento Nacional de Produção Mineral (DNPM, 2013) são 2019 requerimentos para pesquisa mineral, atingindo 14 mil áreas. Em 2009 e 2010 foram 5.600 processos, uma média de 234 requerimentos por mês. Esses números oferecem ao estado o quinto lugar como maior produtor brasileiro de minérios, cujo mapeamento geológico atinge cerca de 65\% do seu território, destaque para a explotação de Urânio, Cromo, Salgema, Magnesita, Níquel, Talco, Cobre, Esmeralda, Ouro e Ferro.

A prospecção e a explotação de urânio no Brasil teve início em 1952, no entanto, o país começa sua produção em 1982, na unidade de Poços de Caldas (MG) ${ }^{6}$, mina que terminou sua produção em 1995. Atualmente, a única mina de urânio em funcionamento no na América Latina encontra-se na

\footnotetext{
${ }^{4}$ Termo usado para a retirada, extração ou obtenção de recursos naturais, geralmente não-renováveis, para fins de aproveitamento econômico, transformação e utilização. Este termo se contrapõe à exploração, que se refere à fase de pesquisa dos recursos naturais. A exploração visa à descoberta, delimitação e definição de tipologia, teores e qualidade da ocorrência do recurso (KOPEZINSKI, 2000).

${ }^{5}$ Conceito associado às pequenas aglomerações e/ou grupos que se organizam geralmente, através de relações personalizadas de parentesco, definidas em termos das grandes aglomerações e/ou de grupos demarcados por relações individuais ou contratuais (MAGALHÃ̈ES, 2000).

${ }^{6}$ Complexo Mínero-Industrial de Poços de Caldas (CIPC), localizado no Planalto de Poços de Caldas, no município de Caldas (MG), atualmente está em fase de descomissionamento com um laboratório, Unidade de Tratamento de Minérios (UTM) (INB, 2013).
} 
província uranífera de Lagoa Real, no município de Caetité. A produção brasileira é apenas para uso nacional. $O$ urânio extraído em Caetité (BA) é enviado na forma de yellowcake para o exterior para ser enriquecido e, ao retornar ao Brasil, segue para a Fábrica de Combustível Nuclear (FCN), onde o combustível nuclear é convertido em pastilhas que preenchem as varetas do elemento combustível (INB, 2013).

A explotação em Caetité (BA) é feita a céu aberto em uma das 33 ocorrências, com cerca de 80 $\mathrm{km}$ de comprimento por 30 a $50 \mathrm{~km}$ de largura. Localizado a $40 \mathrm{~km}$ da sede do município, o complexo instalado denominado Unidade de Concentrado de Urânio - URA (INB, 2013).

Caetité situa-se na Região Econômica da Serra Geral, Mesorregião Geográfica do Centro Sul Baiano, Microrregião de Guanambi, e se divide entre a zona das caatingas, clima semiárido, e a dos gerais (clima seco ou sub-úmido), duas regiões distintas (IBGE, 2013).

O urânio se distribui na crosta terrestre como constituinte da maioria das rochas. É um metal de coloração prateada, radioativo, denso, inflamável, flexível e maleável. É utilizado na indústria bélica e como combustível em usinas nucleares para geração de energia elétrica. Outros usos incluem: medicina nuclear; datação de rochas ígneas; fotografia; fertilizantes à base de fosfatos; e catalisador de reações.

\section{Considerações metodológicas a partir do conceito de paisagem}

De acordo com Kahtouni (2006, p. 46), a palavra "paisagem" remete às origens latinas da palavra paysage do francês, cujo radical (pays) significa "país". Palavra que pode ser entendida como o território de identificação linguística, étnica e cultural de um povo. Os antigos latinos denominavam pagense os terrenos delimitados para a prática de agricultura e resultantes da ação humana de divisão reticulada das centúrias. A palavra "paisagem" e suas raízes associam-se à ideia de fuga em direção ao bucólico, de cenas distantes da cidade. Com o tempo esse conceito foi se modificando, tornou-se parte do cotidiano, estando próxima à urbanização e modificando-se com a intervenção humana através dos tempos.

A partir destas definições que se verificam os conceitos associados à degradação, aos efeitos negativos decorrentes das ações humanas na natureza, mas, além destas, há também os fenômenos, processos naturais que alteram a paisagem.

De acordo com Bitar (1997), a degradação de uma área ocorre quando a vegetação nativa e a fauna são destruídas; a camada fértil do solo for perdida ou removida; e a qualidade e o regime de vazão do sistema hídrico forem alterados. A degradação ambiental ocorre quando há perda de adaptação às características físicas, químicas e biológicas e é inviabilizado o desenvolvimento socioeconômico.

Sobre a degradação na exploração mineral, segundo o autor supracitado, pode ocorrer através de formas diversas, no entanto previstas como poluição visual e sonora, ameaça às edificações próximas com rachaduras, por exemplo, surgimento de áreas desmatadas, erosões, além de outros danos relacionados à paisagem.

Segundo Guimarães (1998), o estudo da paisagem envolve essencialmente sociedade/natureza, as comunidades humanas e seus ambientes, naturais ou construídos. Ela afirma que a paisagem vivida tem como elementos chave a percepção, a experiência e a valoração das dimensões objetivas intrínsecas à vida.

Sauer, (1998) clássico geógrafo, se interessou pelo estudo da paisagem. O autor analisa o significado da paisagem como uma forma da Terra na qual o processo de modelagem não é de modo algum imaginado como simplesmente físico. Ela pode ser, segundo o autor, definida como uma área composta por uma associação distinta de formas, ao mesmo tempo físicas e culturais. Toda paisagem tem uma individualidade, bem como uma relação com outras, e isso também é verdadeiro com relação às formas que a compõem.

Diante do reconhecimento do valor da paisagem, a metodologia apresentada parte da escolha de pontos de vista em campo que traduzem a síntese do ambiente. Para que este diálogo aconteça é 
necessário a compreensão do fenômeno a partir da perspectiva do outro, por meio de uma parceria, interação, intercâmbio de conhecimento e experiência entre pesquisador e pesquisado, por isso optouse pela vivência em campo. Pesquisas qualitativas que dispõem de técnicas semelhantes às utilizadas em metodologias participativas objetivam possibilitar levantar, registrar e sistematizar os conhecimentos (YIN, 2001).

Assim, permanecem algumas questões de cunho metodológico, como: a divulgação das etapas de exploração e processamento dos minérios realizada pela INB em Caetité (BA) esclarecem a questão ambiental que envolve a explotação do urânio? Os moradores de Caetité (BA) possuem conhecimentos sobre radiação?

O registro e a sistematização das informações produzidas por meio de metodologias participativas utilizadas no processo, bem como também de todo o arcabouço metodológico desenvolvido durante a pesquisa, vislumbra a adequação da linguagem, para que ela possa estar em consonância à realidade das comunidades pesquisadas.

\section{A paisagem do município de Caetité (BA)}

As alterações ou implicações advindas da atividade mineral podem provocar maior ou menor efeito ambiental, conforme a localização, o método de lavra, o tipo de minério extraído e o tipo de desmonte utilizado. De acordo com Bacci (2006), os fatores geológicos ligados à localização natural da jazida e ao grande volume das reservas, proporcionam longa vida útil aos empreendimentos, são fatores rígidos e imutáveis que impedem a mudança das áreas de extração.

No contexto de recursos minerais, o município de Caetité (BA) abriga em seu solo riquezas como: ametista, manganês, minério de ferro hematita e urânio. Caetité que possui atualmente 52.000 habitantes (IBGE, 2013), sendo que 40\% destes vivem na zona rural. Segundo o Relatório de Impacto Ambiental (RIMA) do empreendimento, as comunidades do distrito de Maniaçu alvo desse estudo (Juazeiro, Riacho da Vaca e Barreiro), possuem como paisagem o Semiárido nordestino, realidade em que predomina a concentração fundiária, pecuária intensiva, pequena produção agropecuária, relações sociais não capitalistas subordinadas, clientelismo político e indicadores sociais abaixo da média estadual (RIMA, 1997, p. 11).

Com efeito, o sentido mais afetado pela percepção da mineração é o referente ao aspecto visual. No município em estudo, a paisagem gerada pelas cavas, pelo depósito de rejeitos e pelas medidas mitigadoras existentes, a exemplo da reserva florestal, do projeto bosque da amizade, assim como, recuperação das áreas próximas a barragem da usina, cultivo e doação de mudas nativas, manutenção das estradas do Distrito sede da mineradora e fornecimento de água para consumo humano das comunidades vizinhas da mineradora, são elementos notórios, uma vez que, tais ações são reconhecidas pelas comunidades como parte das ações ambientais do empreendimento minerador.

No Município de Caetité (BA), tem se identificado reconfigurações a partir da especulação imobiliária, frente ao conjunto urbanístico e arquitetônico do centro antigo, constituído por imóveis originários do século XIX e início do século XX. As mudanças urbanas começaram com a circulação da riqueza trazida pela explotação dos seus recursos minerais e recente implantação de um parque eólico na região.

Considerando esses aspectos o município estabeleceu frente à mineradora INB algumas parcerias pontuais, baseada em investimentos diversos, como adutora, abertura de poços, reforma da padaria comunitária e da casa de farinha no distrito de Maniaçu, bem como participação na conclusão das obras do centro de pesquisa experimental (área no Distrito de Maniaçu, destinada a pesquisas visando identificar variedades de mandioca e palma que possua maior resistência às pragas e maior produtividade no cultivo).

A mineradora participa também como financiadora da Casa Anísio na sede municipal e possui um espaço conhecido como espaço cultural INB; em parceria com Serviço Nacional de Aprendizagem industrial (SENAI) implantou no Município o projeto Saber Mais para qualificação profissional; além de 
patrocínios financeiros, destinados à realização de festas populares e projetos diversos (INB, 2013) .

Através de "programas/projetos de parceria", a empresa mineradora desenvolve discussões sobre temas variados com alunos da rede pública de ensino do município. De modo geral, as ações realizadas pela empresa mineradora em Caetité (BA) são pontuais como "encontros de formação de educadores", gincanas, palestras sobre temas ambientais, além de programas destinados aos próprios funcionários e respectivos familiares (PROMINER, 2009).

Nesse sentido, o viés capitalista de produção apresenta as atividades de extração mineral como força motriz de dinamização das economias nacionais e locais, uma vez que oferece investimentos em infraestrutura, emprego, elevação das receitas públicas, entre outros. Este foi, e continua sendo, basicamente, o discurso modernizante por meio do qual governos nacionais e locais se apoiam politicamente para justificarem e incentivarem essas atividades (GONZÁLEZ, 2004).

Crescentemente, em oposição a esse discurso, há o debate sobre os efeitos da mineração para as comunidades onde esse tipo de atividade é realizado em larga escala industrial-extrativa. Em termos gerais, as preocupações convergem para os diferentes interesses dos atores envolvidos nesse processo.

\section{Considerações Finais}

Ao abordar aspectos visuais, estéticos, de ordem cênica em uma perspectiva experiencial, simbólica, subjetiva de recepção visual e de (re) significação espacial, própria da relação humana com o espaço, o conceito de paisagem é adequado.

Reafirma-se, portanto que o estudo da paisagem permite diversas abordagens. No presente trabalho, foi apresentado um esboço, buscando esclarecer de forma objetiva, os desdobramentos quanto a reflexão da categoria paisagem na perspectiva dos estudos socioambientais. Assim, o trabalho buscou estabelecer uma relação conceitual de paisagem entre os sistemas naturais e antrópicos a partir da análise da dessas transformações no contexto socioambiental a partir da atividade mineradora.

As mudanças na paisagem ocorreram e continuam ocorrendo de forma acelerada, muitas vezes sem o controle local, devido às políticas de planejamento e gestão efetivas. A atividade mineradora altera a paisagem, por isso, é necessário se pensar estratégias de planejamento, gestão e conservação do patrimônio natural e cultural frente à expansão das atividades capitalistas atuais, que na maioria das vezes, estão pautadas em servir aos interesses externos e interesses locais e regionais que estejam interligados a grupos econômicos e políticos dominantes, cuja ação estratégica atendem particulares desconectados das necessidades e direitos da sociedade local.

Para tanto, compreende-se a necessidade desse estudo, para a produção de conhecimento, bem como, disposição de dados e informações, fornecendo subsídios às argumentações e reivindicações dos movimentos sociais organizados e instituições governamentais que objetivam a construção de políticas públicas consistentes e duradouras. Outra pretensão é que o trabalho forneça dados para o planejamento municipal, suprindo, na medida do possível, a falta de estudos sobre as questões propostas, disponibilizando materiais para subsídio de pesquisas futuras e/ou processos decisórios que tenham como objetivo os interesses coletivos do município.

\section{Referências Bibliográficas}

BACCI, D. C; LANDIM, P. M. B.; ESTON, S. M. Aspectos principais e impactos de pedreira em área urbana. Revista Escola de Minas, Ouro Preto, v. 1 n. 59, pp.47-54, jan. - mar. 2006.

BITAR, O. Y. Avaliação da recuperação de áreas degradadas por mineração na região metropolitana de São Paulo. 1997, 193 f. Tese. (Doutorado em Engenharia) - Curso de Pós-Graduação em Engenharia Mineral, USP, São Paulo, 1997. Disponível em: <http://www.teses.usp.br/teses/ disponiveis/3/3134/tde-25102001-165349/> . Acesso em: 2 fev. 2014. 
BRASIL. Departamento Nacional de Produção Mineral (DNPM). Mineração no Brasil: guia do investidor -2000. Disponível em: <http://www.dnpm.gov.br/guia2000.htm.> Acesso em: 04 jan. 2014.

. Indústrias Nucleares do Brasil (INB). Ministério de Ciência e Tecnologia. Relatório anual 2013. Disponível em: http://www.inb.gov.br Acesso em: 04 fev. 2014.

- Instituto Brasileiro de Geografia e Estatística (IBGE). Perfil dos municípios Brasileiros. Gestão Pública 2002. Ministério do Planejamento, Orçamento e Gestão. Diretoria de Pesquisas Coordenação de População e Indicadores Sociais. Rio de Janeiro. 2013. 122pp. Disponível em: http://www.censo2010.ibge.gov.br Acesso em: 17 jan. 2014.

EIA/RIMA. Complexo Uranífero Mínero-Industrial de Lagoa Real, Caetité/BA. v. IV. Relatório de Impacto Ambiental. 195 p. Indústrias Nucleares do Brasil. Planejamento Ambiental e Arquitetura Ltda. Planarq, Salvador, 1997.

GUIMARÃES, S. T. L. Ecoturismo: percepção, valores e conservação da paisagem. Caderno de Geografia, PUC - Belo Horizonte, MG. V. 8, n. 10, fev. 1998.

GONZÁLEZ, P. Distribuindo os benefícios da mineração através dos royalties. Centro Internacional de Investigação para o desenvolvimento (IDRC), Montevideo, 2004. Série Mineração e Desenvolvimento Sustentável, $n 2$ (Royalties da mineração). Disponível em: <http://idlbnc.idrc.ca/dspace/bitstream/10625/30708/13/122482.pdf> Acesso em: 04 fev. 2014.

KAHTOUNI, S. Bases conceituais para a pesquisa: infraestrutura urbana e qualidade ambiental paisagística. Pós - Revista do Programa de Pós-Graduação em Arquitetura e Urbanismo da FAU-USP, n 19, p. 46, São Paulo, 2006.

KOPEZINSKI, I. Mineração x meio ambiente: Considerações legais, principais impactos ambientais e seus processos modificadores. Porto Alegre: Universidade/UFRGS, 2000.

MAGALHÃES, S. B. Projeto de intervenção em uma sociedade camponesa: uma leitura sobre "hortas comunitárias". In: HÉBETTE, J.; NAVEGANTES, R. S. (Orgs.). CAT - ano décimo: etnografia de uma utopia. Belém: UFPA, CAT, 2000.

PROMINER PROJETOS, LTDA. Estudo de impacto ambiental. São Paulo: Bunge Fertilizantes, 2009.

SANTOS, M. Metamorfoses do espaço habitado. 5. ed. São Paulo: Hucitec. 1996.

SAUER, C. O. A morfologia da paisagem. In: CORRÊA, R. L.; ROSENDAHL, Z. (Orgs.). Paisagem, tempo e cultura. Rio de Janeiro: EDUERJ, 1998. p.12-74.

YIN, R. K. Estudo de caso-Planejamento e métodos. 2. ed. Porto Alegre: Bokman, 2001. 